\title{
RECURSOS ESTRATÉGICOS PARA VANTAGEM COMPETITIVA SUSTENTÁVEL EM FOOD TRUCKS
}

\author{
STRATEGIC RESOURCES FOR SUSTAINABLE COMPETITIVE ADVANTAGE OF FOOD TRUCKS \\ RECURSOS ESTRATÉGICOS PARA LA VENTAJA COMPETITIVA SOSTENIBLE EN FOOD TRUCKS
}

VALMIR EMIL HOFFMANN

Doutor

Universidade de Brasília - Brasil ehoffmann@unb.br

ARTHUR MALIMPENSE LEONELO

Bacharel

Trainee na Lojas Riachuelo arthur.m.leonelo@gmail.com

CLEIDSON NOGUEIRA DIAS

Doutor

Empresa Brasileira de Pesquisa Agropecuária - Brasil cleidson_nogueira@yahoo.com.br

ISAAC MATIAS

Doutorando

Universidade Federal do Pará - Brasil

isaac@ufpa.br

Submetido em: 05/05/2016

Aprovado em: 15/08/2016

Doi: alcance. v23n3.p352-371

\section{RESUMO}

O Food Truck chegou recentemente no Brasil e devido ao relevante papel socioeconômico das Micro e Pequenas Empresas (MPE), faz-se necessário compreender melhor esse tipo de empreendimento. Para isso aplicou-se a Visão Baseada em Recursos (VBR). $O$ presente estudo tem como objetivo identificar os recursos que são a fonte de vantagem competitiva sustentável, possibilitando aos Food Trucks desempenho acima da média. A pesquisa é qualitativa e de caráter descritivo, tendo como método o estudo de caso e a coleta de dados foi por meio de entrevistas semiestruturadas e observação. 0 estudo revelou que o conjunto de recursos geradores de vantagem competitiva é variado dentro das organizações pesquisadas. Assim, os recursos que mais se destacaram como potenciais geradores de vantagem competitiva sustentável foram: modelo do truck, matéria-prima exclusiva, geração de energia, equipamentos, network, conhecimento técnico dos funcionários, bom atendimento, receita própria, reputação da empresa e investimentos, cujo bom atendimento foi o único recurso estratégico comum às quatro empresas estudadas.

Palavras-chave: Vantagem competitiva. Visão Baseada em Recursos (VBR). Food Truck.

\section{ABSTRACT}

The Food Truck is a recent arrival in Brazil. Due to the important socioeconomic role of Micro and Small Enterprises (MSEs), it is necessary to better understand this type of project. For this purpose, the Resource Based View (RBV) was applied. This study aims to identify the resources that are a source of sustainable competitive advantage, 
enabling the good performance of Food Trucks. The research is qualitative and descriptive, using a case study. Data were collected through semi-structured interviews and observation. The study revealed that the competitive advantage of the set of resources that generate competitive advantage varies among the organizations surveyed. The features that most stood out as potential generators of sustainable competitive advantage were: the truck model, exclusive raw material, power generation, equipment, network, technical knowledge of the staff, good service, its own revenue, the company's reputation and investments, its good service being the only strategic resource that all four of the companies studied had in common.

Keywords: competitive advantage. Resource-Based View (RBV). Food Truck.

\section{RESUMEN}

El Food Truck llegó recientemente a Brasil y debido al relevante papel socioeconómico de las Micro y Pequeñas Empresas (MPE) se hace necesario comprender mejor ese tipo de emprendimiento. Para ello se aplicó la Visión Basada en Recursos (VBR). El presente estudio tiene como objetivo identificar los recursos que son la fuente de ventaja competitiva sostenible, posibilitando a los Food Trucks un desempeño superior a la media. La investigación es cualitativa y de carácter descriptivo, utiliza como método el estudio de caso y la recolección de datos fue por medio de entrevistas semiestructuradas y observación. El estudio reveló que el conjunto de recursos generadores de ventaja competitiva dentro de las organizaciones estudiadas es variado. Así, los recursos que más se destacaron como potenciales generadores de ventaja competitiva sostenible fueron: modelo del truck, materia prima exclusiva, generación de energía, equipamientos, network, conocimiento técnico de los empleados, buena atención, receta propia, reputación de la empresa e inversiones. La buena atención fue el único recurso estratégico común a las cuatro empresas estudiadas.

Palabras clave: Ventaja competitiva. Visión Basada en Recursos (VBR). Food Truck.

\section{INTRODUÇÃO}

Em um cenário mais competitivo, as empresas de menor porte passam a sofrer forte pressão, para se adaptarem cada vez mais rápido às exigências impostas pelo mercado. A capacidade de resposta das empresas às mudanças é condição essencial para sobrevivência delas. No Brasil, é muito importante o papel socioeconômico desempenhado pelas Micro e Pequenas Empresas (MPE). De acordo com o Serviço Brasileiro de apoio às Micro e Pequenas Empresas (SEBRAE) em pesquisa realizada entre 2000 e 2011, as MPE representam 99\% do número total de empresas formais no país.

Ainda segundo o SEBRAE (2014), as MPE vêm progressivamente aumentando sua relevância na economia brasileira. Constatou-se que, em termos agregados, a participação delas no produto interno bruto (PIB) do país era de $21 \%$ em 1985, aumentou para 23\% em 2001 e para $27 \%$ em 2011. Ou seja, mais de um quarto do PIB brasileiro é gerado pelos pequenos negócios que, para manterem-se no mercado com competitividade, como no caso do Brasil, implementaram variados tipos de estratégias.

Para Mintzberg (1973), a estratégia em pequenas empresas se distingue desde seu processo de formulação. Ele afirma que o processo de formulação de estratégia em pequenas empresas é guiado pela procura ativa por oportunidades, as decisões geralmente são ousadas e concentradas nas mãos do chefe executivo, além da empresa objetivar o crescimento.

Assim, enquanto Porter (1991) afirma que a estratégia está preocupada com objetivos de longo prazo e os meios para alcançá-los que afetam o sistema, Barney (1991) traz uma perspectiva mais endógena de estratégia, com fácil aplicação na perspectiva das MPEs, cujo padrão de alocação de recursos é que permite às empresas manterem ou melhorarem o seu resultado, criando assim a Visão Baseada em Recursos (VBR), que examina a ligação entre características internas de uma empresa e seu desempenho.

Quando se fala em estratégia em pequenas empresas, pode-se estar considerando distintos negócios, em vários setores, como o de alimentação, em que um distinto modelo de negócio, chamado de Food Truck, surgiu como opção para muitos proprietários de restaurantes nos Estados Unidos da América. Esse modelo se 
apresentou como uma alternativa mais simples e a um custo mais baixo, se comparado à abertura ou à manutenção de um restaurante físico.

O modelo, segundo pesquisa realizada pelo Institut Emergent Research nos EUA, consiste em um espaço móvel que transporta e vende comida e/ou bebidas por meio de uma gastronomia de qualidade (gourmet, elaborada) pautada na valorização de alimentos frescos, locais, muitas vezes orgânicos e preferência por um negócio pequeno, sustentável e com design atrativo. No Brasil, os primeiros empreendedores começaram a trazer o modelo de negócio para o país em 2012, na cidade de São Paulo. Hoje já é possível encontrar Food Trucks em todas as capitais brasileiras devido ao grande crescimento desses empreendimentos, em 2013, quando foi sancionada a lei no 15.947/2013 que regulamenta a atividade dos Food Trucks na cidade de São Paulo.

Nesse contexto, desenvolve-se o estudo tendo por base a literatura de estratégias em PME e a Visão Baseada em Recursos (VBR). A questão que norteia o trabalho é: Quais os recursos competitivos existentes nos Food Trucks que são fontes de vantagem competitiva sustentável e possibilitam um desempenho acima da média?

Logo, por se tratar de um modelo de negócio tão recente no país, existe uma carência de estudos que visam compreender melhor esse tipo de empreendimento. Logo, o presente estudo tem como objetivo identificar os recursos que são a fonte de vantagem competitiva sustentável, possibilitando aos Food Trucks desempenho acima da média. Para alcance desse objetivo geral, esta pesquisa teve os seguintes objetivos específicos: i) caracterizar o mercado de oferta de Food Trucks na cidade de Brasília; ii) selecionar, dentro do universo de Food Trucks encontrados, os empreendimentos que obtiveram desempenho (faturamento) acima da média por meio da TVF - Taxa de variação do faturamento; iii) Identificar os recursos existentes nos empreendimentos selecionados; e iv) identificar recursos estratégicos comuns aos empreendimentos que obtiveram alto desempenho.

Assim, a justificativa desta pesquisa se dá pela importância do crescimento dos Food Trucks no contexto nacional, que é evidenciado por seu próprio caráter de MPE e a sua rápida expansão pelas capitais brasileiras. À medida que a carência de estudos sobre os Food Trucks é uma realidade e levando em consideração sua relevância, é importante que os estudos acerca do tema estendam-se ao campo da estratégia coorporativa, a fim de compreender os mecanismos que garantirão vantagem competitiva sustentável, consequentemente sua sobrevivência e expansão no mercado. Hexsel e Lagreca (2007) afirmam que uma das circunstâncias que dificulta o desenvolvimento das MPE é que essas tendem a atuar em setores fragmentados, em que são baixas as barreiras à entrada, o processo competitivo é intenso e, por consequência, os lucros médios são baixos.

Nessa situação, o desempenho de uma empresa depende, de forma mais significativa, das ações que desenvolve a partir de seus recursos internos e, menos, do ambiente. Neste cenário, a utilização da visão baseada em recursos (VBR) apresentada por Barney (1991) e amplamente aceita pela comunidade científica está fortemente adequada à realidade do presente estudo.

\section{REFERENCIAL TEÓRICO}

\subsection{Vantagem Competitiva Sustentável}

Qualquer produtor que vende seus produtos ou serviços, gerando lucro, dispõe de uma vantagem competitiva com os consumidores que optaram por comprar dele e não de seus competidores. Apesar de a vantagem competitiva resultar de uma diferenciação entre os competidores para que um produtor desfrute de uma vantagem competitiva em um produto ou segmento de mercado, a diferença ou as diferenças entre os competidores devem ser sentidas pelo próprio mercado e nos atributos de produto/entrega considerados critérios fundamentais de compra pelo mercado (COYNE, 1986).

Segundo Coyne (1986), se uma vantagem competitiva significativa ocorre em função da diferença nos atributos importantes baseados em uma subjacente lacuna de capacidade, então a sustentabilidade da vantagem competitiva está simplesmente em função da durabilidade de ambos, os atributos e a lacuna.

A condição mais importante para a sustentabilidade é que competidores existentes e potenciais não possam ou não irão assumir as ações necessárias para fechar a lacuna. Se os competidores podem e vão preencher a lacuna, a vantagem é por definição não sustentável (Coyne, 1986, p. 58). 
Para Porter (1989, p. 2), "A vantagem competitiva surge fundamentalmente do valor que uma empresa consegue criar para seus compradores e que ultrapassa o custo de fabricação pela empresa". A vantagem competitiva pode vir de uma liderança em custos ou de uma estratégia de diferenciação, e o valor gerado destas estratégias deve ser superior ao valor gerado pela concorrência. Mas este é o resultado de um processo, pois de acordo com Porter (1989), a vantagem competitiva deve ser compreendida não pela análise da empresa, mas sim pelas diversas atividades que uma organização executa, como marketing, logística, recursos humanos, entre outras.

No que tange à vantagem competitiva, na visão de Porter (1989), as diferenças de desempenho econômico estão relacionadas aos aspectos externos das firmas, tais como competição do mercado, localização e posicionamento estratégico. Para Barney (1991), o desempenho econômico superior é proporcionado pela vantagem competitiva obtida em função da heterogeneidade e imobilidade dos recursos organizacionais. Então, há vantagem competitiva "quando a empresa dispõe de recursos e competências raros e difíceis de imitar que a permitam oferecer benefícios superiores ou que tragam uma vantagem no custo" (MOHR et al., 2011, p. 53).

Assim, enquanto a vantagem competitiva (VC) ocorre quando se está implementando uma estratégia de criação de valor que não está sendo implementada ao mesmo tempo por seus competidores, a vantagem competitiva sustentável (VCS) ocorre quando os competidores não possuem a capacidade de executar essa estratégia (BARNEY, 1991).

Logo, a definição de VCS adotada nesta pesquisa é quando se está implementando uma estratégia de criação de valor que não está sendo simultaneamente executada pelos concorrentes atuais ou potenciais, juntamente com a incapacidade de duplicarem os benefícios dessa estratégia (BARNEY, 1991; HOFFMAN, 2000).

A seguir é explicado o modelo apresentado por Barney (1991) sobre fontes de vantagem competitiva sustentável por meio da visão baseada em recursos (VBR).

\subsection{Visão Baseada em Recursos}

Recursos empresariais incluem todos os ativos, capacidades, processos organizacionais, atributos empresariais, informação, conhecimento, etc., controlados pela empresa que a permite conceber e implementar estratégias que melhorem a eficiência e a eficácia (DAFT, 1983). Os recursos são ativos tangíveis e intangíveis que a empresa controla e que podem ser usados para criar e implementar estratégias (BARNEY, 1991). Nesse sentido, a Visão Baseada em Recursos (VBR) fundamenta-se nos recursos como base para a estratégia da firma e leva em consideração às competências capacidades e habilidades como base do conhecimento produtivo da empresa; fonte de vantagem competitiva (KRETZER; MENEZES, 2006).

Alguns dos recursos com os quais as organizações competem não são ativos encontrados para negociação no mercado. Assim, para que a empresa desenvolva a sua estratégia de mercado, é necessário que ela construa seus recursos (DIERICKX; COOL, 1989). Dessa maneira, pela VBR, a empresa enfatiza seus recursos que incluem habilidades tácitas, padrões de cooperação e bens intangíveis que precisam de tempo e aprendizado para desenvolverem-se. A VBR também é útil na identificação de recursos que proporcionam a geração ou a perenidade da vantagem competitiva entre firmas, já que inclui todos os atributos que capacitam as redes definir e implementar estratégias (BARNEY, 1991).

Por isso, a visão baseada em recursos (VBR) estende o conceito de cadeia de valores à medida que examina os atributos que os recursos isolados por essas cadeias devem possuir para que sejam fonte de vantagem competitiva sustentável (BARNEY, 1991), pois são seus recursos e serviços construídos que, na visão de Penrose (1959), possuem a capacidade de gerar retornos (HERZOG, 2001; KRETZER; MENEZES, 2006).

Segundo Barney (1991), as empresas que são capazes de acumular recursos valiosos, raros, difíceis de imitar e não substituíveis (modelo VRIS), alcançam uma vantagem competitiva sobre as empresas concorrentes, pois buscam aumentar e não necessariamente maximizar seu desempenho, causando, assim, sucesso diferenciados entre si (KRETZER e MENEZES, 2006).

Pela importância que os recursos construídos pela empresa têm na manutenção de sua competitividade e sobrevivência, passaram a caracterizar-se, mais recentemente, como valiosos, raros, difíceis de imitar e explorados pela organização (modelo VRIO) (BARNEY; CLARK, 2007). Para Gonçalves, Coelho e Souza (2011), a alteração do modelo VRIS para o modelo VRIO aparece no livro publicado por Barney e Clark (2007), cujos indicadores dos tipos de recursos são abordados de uma forma levemente modificada. Os três primeiros foram 
praticamente mantidos, porém o último, a substitutabilidade (S), foi trocado pela organização (0). Assim, o modelo atual (VRIO) parece ter sido apresentado de forma a permitir uma maior aproximação entre a teoria e a prática.

Como representado pelo Quadro 1, Barney e Clark (2007) estruturaram o modelo VRIO com base em quatro dimensões ou questões que devem ser consideradas sobre um recurso para determinar seu potencial competitivo: Valor, Raridade, Imitabilidade e Organização, sendo que a resposta para essas questões seria determinante para averiguar o grau de vantagem competitiva lograda pelo recurso, bem como sua sustentabilidade.

Além disso, pesquisas nacionais mais recentes contribuem com a revisão da literatura, na qual a pesquisa de Hayashi, Baraniuk e Bulgacov (2006) procurou identificar e caracterizar os principais recursos utilizados para execução de mudanças de conteúdo estratégico em três pequenas empresas de massas alimentícias, bem como avaliar os impactos destes recursos sobre as suas vantagens competitivas. Foi possivel constatar que os recursos considerados fontes de vantagem competitiva foram a arquitetura estratégica e a reputação. Já o estudo feito por Pavão, Sehnem e Hoffmann (2011) analisou a relação entre os recursos valiosos, inimitáveis, raros e organizáveis e a vantagem competitiva sustentável (VCS) em duas organizações. Na primeira organização os recursos encontrados que geradores de vantagem competitiva variam entre: físicos, humanos e organizacionais. Já para a segunda organização estudada destacam-se os recursos físicos e humanos.

Quadro 1: Estimando o potencial de retorno dos recursos organizacionais

\begin{tabular}{|c|c|c|c|c|c|c|c|}
\hline \multirow{5}{*}{ 总 } & $\begin{array}{l}\text { Recurso } \\
\text { Valioso? }\end{array}$ & $\begin{array}{l}\text { Recurso } \\
\text { Raro? }\end{array}$ & $\begin{array}{c}\text { Recurso } \\
\text { Dispendioso } \\
\text { de Imitar? }\end{array}$ & $\begin{array}{l}\text { Recurso é } \\
\text { Explorado na } \\
\text { empresa? }\end{array}$ & $\begin{array}{l}\text { Categoria } \\
\text { competitiva }\end{array}$ & $\begin{array}{c}\text { Desempenho } \\
\text { Econômico }\end{array}$ & $\begin{array}{c}\text { Categoria } \\
\text { Swot }\end{array}$ \\
\hline & Não & - & - & Não & $\begin{array}{c}\text { Desvantagem } \\
\text { Competitiva }\end{array}$ & $\begin{array}{c}\text { Abaixo do } \\
\text { Normal }\end{array}$ & Fraqueza \\
\hline & Sim & Não & - & - & $\begin{array}{c}\text { Paridade } \\
\text { Competitiva }\end{array}$ & Normal & $\begin{array}{l}\text { Força ou } \\
\text { Fraqueza }\end{array}$ \\
\hline & Sim & Sim & Não & - & $\begin{array}{c}\text { Vantagem } \\
\text { Competitiva } \\
\text { Temporária }\end{array}$ & $\begin{array}{c}\text { Acima do } \\
\text { Normal }\end{array}$ & $\begin{array}{c}\text { Força e } \\
\text { competência } \\
\text { distintiva }\end{array}$ \\
\hline & Sim & Sim & Sim & Sim & $\begin{array}{l}\text { Vantagem } \\
\text { Competitiva } \\
\text { Sustentável }\end{array}$ & $\begin{array}{c}\text { Acima do } \\
\text { Normal }\end{array}$ & $\begin{array}{c}\text { Força e } \\
\text { competência } \\
\text { distintiva de } \\
\text { longo prazo }\end{array}$ \\
\hline
\end{tabular}

Fonte: Barney e Hesterly (2007, p. 80).

Gohr et al. (2011) analisaram os recursos estratégicos de uma organização do setor sucroalcooleiro e mostraram que, embora todos os recursos fossem explorados pela firma, alguns não permitam o desenvolvimento de uma vantagem competitiva sustentável (VCS). Os recursos que garantiram a vantagem competitiva sustentável como os físicos: caldeiras com grande capacidade de operação e condições agronômicas; humanos: mão de obra qualificada; e os recursos organizacionais: conhecimento empresarial e preocupação socioambiental.

A visão baseada em recursos também foi utilizada para investigar a Santos Brasil, empresa que é referência no setor de logística portuária no país, cujo trabalho de Barcelos, Marcon e Mello (2011) buscou compreender a combinação dos recursos e das capacidades dessa empresa para obtenção da vantagem competitiva sustentada. Os resultados mostraram que são os recursos físicos os mais importantes para a firma por serem fontes de vantagem competitiva sustentável, identificando-se os seguintes recursos: localização estratégica; equipamentos de ponta; sinergias operacionais; estratégia de liderança em tecnologia; e investimentos continuados em estrutura física.

Por fim, Hexsel e Lagreca (2007) elaboraram um estudo com o objetivo central de identificar como a Baldo, uma MPE que atua em um setor fragmentado, desenvolveu uma estratégia que lhe possibilitasse vantagem competitiva sustentável. Como resultado, os recursos que possibilitaram a geração de vantagem competitiva para 
a organização estudada foram: alto volume de estoques intermediários, imagem da marca, e sistema de distribuição.

Assim, mesmo que a empresa possua recursos e capacidades, eles, por si só, não garantirão um desempenho acima da média, isso só será possível se a empresa possuir recursos raros e valiosos e os interagir com sua estratégia adotada, alinhados com seus recursos e capacidades que impactam positivamente no seu desempenho (RIBEIRO; ROSSETO; VERDINELLI, 2011), realizando mudanças em suas rotinas operacionais por meio de uma estratégia ambiental proativa, que é uma competência organizacional, na condução da coordenação de seus recursos técnicos, humanos e heterogêneos para manter ou incrementar sua competitividade e seu desempenho (ARAGÓN-CORREA et al., 2008).

\section{METODOLOGIA}

Esta seção mostra os aspectos metodológicos em termos de técnicas de pesquisa e análises adotadas para a execução do trabalho. Cabe ressaltar a inexistência de um método melhor ou pior que outro, mas que se deve buscar o melhor arranjo entre método, objetivo e as condições nas quais a pesquisa está sendo realizada (YIN, 2010).

\subsection{Delineamento da Pesquisa}

A pesquisa realizada é de cunho qualitativo e de caráter descritivo. A técnica escolhida para a execução da pesquisa foi o estudo de caso. A escolha dessa técnica se deu pela necessidade de entender vínculos causais dentro de um contexto real, pois se busca identificar recursos que são responsáveis pela geração de vantagem competitiva sustentável dentro do objeto de estudo, os Food Trucks.

Estudo de caso é uma pesquisa empírica que investiga um fenômeno contemporâneo em seu contexto real, quando os limites entre o fenômeno e o contexto não são claramente evidentes e no qual várias fontes de evidências são utilizadas (YIN, 2010).

De acordo com Bruyne (1991) e Triviños (1994), o estudo de caso é uma opção, quando se pretende pesquisar em profundidade uma ou mais organizações com grande quantidade de informações e riqueza de detalhes, visando assimilar a totalidade da situação.

Ainda assim, dentro do método escolhido optou-se pelo estudo de multicasos, pois ele possibilita 0 desenvolvimento da triangulação à medida que obtém informações de diferentes organizações. A triangulação, segundo Yin (2010), possibilita que qualquer descoberta ou conclusão em um estudo de caso seja mais convincente e acurada.

A cidade de Brasília é o lócus da presente pesquisa. Sendo assim, procurou-se identificar todos os Food Trucks existentes atualmente na cidade. Diante do fato de que existem vários negócios considerados "carrinhos de rua" tradicionais na cidade de Brasília, utilizou-se a definição de Food Truck como um espaço móvel que transporta e vende comida e/ou bebidas por meio de uma gastronomia de qualidade (gourmet, elaborada), pautada na maioria dos casos na valorização de alimentos frescos, locais, muitas vezes orgânicos e preferência por um negócio pequeno, sustentável ou com design atrativo.

\subsection{Unidade de Análise e Seleção dos Casos}

É possível observar uma explosão de crescimento do número de Food Trucks no Distrito Federal a partir do ano de 2014, quando o modelo passou a ser mais difundido pelo país ocupando espaços em veículos de comunicação, notícias e eventos. Esse modismo que ele adquiriu a partir de 2014 contribuiu de maneira expressiva para o alto crescimento do modelo. 0 Gráfico 1 mostra essa curva de crescimento: 


\section{Gráfico 1: Crescimento do número de Food Trucks no DF ao longo dos anos}

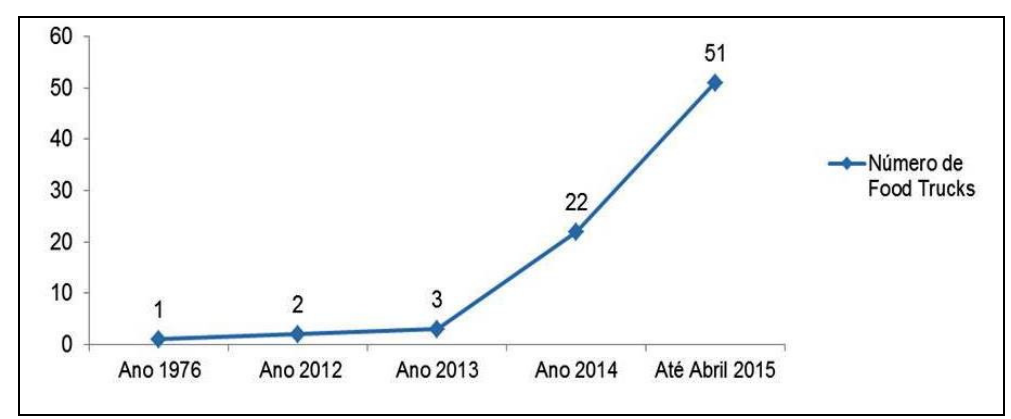

Fonte: Elaboração própria a partir de dados da pesquisa.

Considerando apenas empreendimentos que se encaixassem na definição de Food Truck delineada nesta pesquisa (item 3.1), foi possível identificar um universo de 51 Food Trucks até abril de 2015, a saber: 1) Vai Bem (Gelados); 2) Dona Esponja; 3) Vinny's (artisan pizza); 4) El Perro Negro; 5) Pastéis da Tia Neuza; 6) Zagaia; 7) Bistruck; 8) Tony's American Street Food; 9) Bistrô Itinerante; 10) Sucopira; 11) Los Batateiro's; 12) Kim Kebab; 13) Belgrado Burger; 14) Crepe Voyage; 15) Malibu; 16) Arroz Carreteiro (food truck); 17) Los Kactus; 18) Geléia Burger; 19) Chilli na Rua; 20) Açaí da Capital; 21) Kombinni Coffee Truck*; 22) Dozai Urban Food; 23) Burger Truck; 24) Potatoes e Batatas; 25) Fusbier; 26) Churros do Tio; 27) Le Hotdog Parisien et Crepe; 28) Maria Gulosice; 29) Corina; 30) Shukran Rock \& Food; 31) Naked Barbecue; 32) Baguet's Truck; 33) Mexicoletas; 34) Raf Food Truck; 35) Komboleria; 36) Ribs on the Truck; 37) Operação Pizza; 38) Corujinha Food Truck; 39) Hamburgueria do Francês; 40) Dona Fininha; 41) Divina Tapioca; 42) Sushi Dog; 43) Como Food Truck; 44) Açaí Truck; 45) Poutinerie do Rondy; 46) Mix Açaí; 47) Gutrailler; 48) Braz Bier; 49) Fresh Food Truck; 50) Garapa Food Truck; e 51) Latifas Food Truck.

Para determinar os casos a serem estudados, foi definido que o empreendimento deveria possuir funcionamento mínimo de seis meses. Isso garante que o proprietário tenha experiência e vivência mínima suficiente para contribuir de forma eficaz com a pesquisa.

Os empreendimentos selecionados para o estudo deveriam apresentar também desempenho acima da média da concorrência, pois isso atenderia uma condição alinhada ao objetivo da pesquisa. Esse desempenho foi medido com base na variação do faturamento dos empreendimentos, por meio da TVF (taxa de crescimento do faturamento). A avaliação da TVF foi feita entre novembro de 2014 e abril de 2015 e essa taxa foi calculada de acordo com a fórmula que segue, onde 'Ff' representa o faturamento final (em abril de 2015) e 'Fi' representa 0 faturamento inicial (em novembro de 2014).

$$
T V F=\left(\frac{\mathrm{Ff} .100}{\mathrm{Fi}}\right)-100
$$

Feito o cálculo da TVF para os empreendimentos que estão em atividade por um período mínimo de seis meses, calculou-se a taxa de crescimento do faturamento média (TVFM) entre esses empreendimentos. $O$ cálculo é representado na fórmula que segue, onde $n$ representa o número de empreendimentos e $\sum_{i=1}^{n} T V F i$ representa o somatório das taxas de crescimento do faturamento de cada empreendimento:

$$
T V F M=\frac{\sum_{i=1}^{n} T V F i}{n}
$$

Assim, apenas os empreendimentos que apresentassem uma TVF superior a TVFM seriam considerados para o estudo. Por fim, para que pudesse ser feita uma comparação mais efetiva, os Food Trucks selecionados para a amostra deveriam cumprir mais um requisito, estarem dentro da mesma categoria de produto. Dessa forma, optou-se pelos Food Trucks que estivessem dentro da categoria de refeição.

Em resumo dos critérios para a seleção dos casos encontram-se: i) Mínimo seis meses de funcionamento; ii) TVF acima da média; e iii) Categoria: refeição. 
Tabela 1: Amostra da pesquisa

\begin{tabular}{|l|l|l|l|}
\hline Food Trucks & Especialidades & Data de Inauguração & TCF (\%) \\
\hline El Perro Negro & Hot-Dog (Artesanal) & $29 / 10 / 2014$ & 112,77 \\
\hline Belgrado Burger & Hambúrguer Artesanal & $30 / 10 / 2014$ & 128,57 \\
\hline Burger Truck & Hambúrguer Artesanal & $29 / 03 / 2014$ & 66,62 \\
\hline Ribs on the Truck & Culinária Uruguaia Artesanal (pratos e sanduíches) & $06 / 2014$ & 72,18 \\
\hline
\end{tabular}

Fonte: Dados da Pesquisa.

Da lista completa dos cinquenta e um Food Trucks que foram identificados, analisaram-se suas especialidades, data de inauguração e TVF. Sendo assim, os Food Trucks que atenderam os requisitos utilizados neste estudo encontram-se na Tabela 1.

\subsection{Fonte, Coleta e Análise dos Dados}

Visando responder ao primeiro objetivo específico da presente pesquisa, foi realizada uma busca por Food Trucks através de redes sociais (páginas dos empreendimentos e eventos gastronômicos no DF), sites como: http://www.foodtrucknasruas.com.br/ e http://www.agendafoodtruck.com.br/brasilia/, por fim, comparecimento em eventos gastronômicos em Brasília, como: "Food Truck nos Eixos" e "Chef nos Eixos".

Para obter as informações necessárias ao cumprimento do segundo objetivo específico, foi efetuado um contato direto com os proprietários dos Food Trucks por meio de: página oficial em rede social (Facebook); e-mail; contato telefônico e encontros presenciais. Foi solicitada a data de início das atividades do empreendimento. Para aqueles que possuíssem um mínimo de seis meses de funcionamento, foi solicitada uma segunda informação, a taxa de variação do faturamento (TVF) entre novembro de 2014 e abril de 2015.

Já a coleta das evidências necessárias para responder ao objetivo específico três foi feita, principalmente, por meio de entrevista em profundidade semiestruturada com os proprietários dos Food Trucks definidos no estudo (P1, P2, P3 e P4). Uma das entrevistas foi feita em inglês pelo fato de o proprietário ser um estrangeiro e não ter o domínio da língua portuguesa. Ainda foi feita uma entrevista com o presidente da associação brasiliense de Food Truck (P5), com o objetivo de caracterizar o mercado, mais precisamente a categoria de Food Trucks. Foi também utilizada de maneira complementar a observação direta não participante, já que, como afirma Yin (2010), ao realizar uma visita de campo ao local escolhido para o estudo de caso será possível encontrar disponíveis para observação alguns comportamentos ou condições ambientais importantes. Assim, a fonte dos dados foi primária.

Para a condução da entrevista semiestruturada foi elaborado um roteiro (Vide Anexo 1) alinhado com os conceitos de recursos apresentados por Barney (1991), o modelo VRIO de Barney e Clark (2007) e os estudos encontrados que aplicaram o modelo.

Por fim, utilizou-se das informações obtidas na entrevista por meio de uma categorização a partir das dimensões concorrência, desempenho e recursos (capital físico, capital organizacional, financeiro) descritos no Anexo 1, e foi feita uma comparação entre os estabelecimentos estudados a fim de atingir o quarto objetivo específico da pesquisa.

\section{RESULTADOS}

\subsection{Caracterização do mercado de oferta}

Após a realização das entrevistas, pode-se obter uma série de informações e percepções a respeito do mercado de Food Trucks. Na categoria mercado, de acordo com o presidente da associação brasiliense de Food Truck (P5), o mercado de Food Trucks em Brasília, assim como em todo o país, é uma novidade e está em franca expansão "Cresce absurdamente a cada dia". Apesar de alguns entrevistados reiterarem o crescimento do setor, como é o caso do proprietário P3: "O mercado de Brasília começou a se desenvolver muito rapidamente após ter chegado a São Paulo." E ainda o proprietário P5 "O mercado de Food Trucks é crescente [...] está na moda, pessoas falam sobre ele na TV, está constantemente nas notícias.", alguns proprietários ressaltam que muitas vezes esse crescimento acontece de maneira desordenada. A proprietária P1 afirma: "A gente percebe um 
crescimento desordenado do número de food trucks, pois não há padronização de qualidade e diversidade da oferta.". Já o proprietário P2 ressalta que, devido à falta de regulamentação que está a caminho, muitos entram no mercado sem cumprir uma série de características que pertencem ao modelo - "[...] muitos empreendimentos entram no mercado intitulando-se food trucks quando na verdade não o são".

De acordo com P5, existe um trabalho da associação junto ao governo do distrito federal, que teve início em setembro de 2014, para que seja criada uma regulamentação para o modelo. Ele ressalta que, atualmente, a minuta desse projeto de lei está cerca de $60 \%$ concluída. Ele ainda informa que esse projeto partiu de uma iniciativa da Associação Brasiliense de Food Truck (ABFT) em parceria com a Secretaria de Trabalho. Foram convocados para discussão do projeto órgãos como Agência Nacional de Vigilância Sanitária (ANVISA), Secretaria de Saúde, Departamento de Trânsito (DETRAN), Bombeiros, Secretaria do Turismo, Administração de Brasília, entre outros. O Proprietário 5 afirma que existe um reconhecimento dos próprios órgãos a respeito do modelo de negócio: "Eles mesmos entendem e reconhecem que é um modelo de negócio gerador de emprego, formador de opinião e que consegue mobilizar um número muito grande de clientes".

A própria ABFT contribuiu ativamente com o SEBRAE Nacional para o desenvolvimento de um modelo de negócios para a criação de um Food Truck. Esse modelo já foi disponibilizado para todo o país e pode ser encontrado no sítio do SEBRAE através do hipervínculo: http://www.sebrae.com.br/sites/PortalSebrae/artigos/ Food-Truck:-uma-nova-tend\%C3\%AAncia.

Ao questionar os entrevistados a respeito de sua percepção em relação à concorrência, percebe-se uma convergência de opiniões no que diz respeito aos restaurantes. Na categoria concorrência, grande parte dos entrevistados afirma que não consideram os restaurantes como concorrentes uma vez que a necessidade atendida pelos Food Trucks é distinta da necessidade atendida por eles. A proprietária P1 afirma: "O cliente que procura um restaurante está disposto a gastar mais e dispor de maior tempo para refeição". Já o proprietário P3 ressalta: "[...] muitos clientes gostam de comer aqui por não ter toda a burocracia que existe em um restaurante e ainda assim encontrar qualidade".

Para o presidente da associação (P5), falar de concorrência para esse modelo tão novo de negócio é algo delicado. Segundo ele, ainda que esse modelo esteja dentro da categoria de alimentação fora do lar, como fast foods e restaurantes, a experiência que um restaurante oferece é mais distinta do que os food trucks oferecem, ao mesmo tempo em que os fast foods não possuem a mobilidade e a qualidade que esse modelo possui.

No que diz respeito à competição interna, dentro dessa categoria, alguns proprietários reconhecem que, apesar de existir uma concorrência, o setor trabalha de uma forma muito integrada e complementar. Segundo a proprietária P1, eles estão sempre buscando dividir espaços com outros trucks que se complementam em termos de produtos oferecidos e isso é feito de maneira recorrente e organizada. Já P5 afirma: "Food truck é uma grande família, $80 \%$ dos trucks que estão em Brasília se falam com absurda frequência, existem grupos de whatsapp onde todos estão inseridos".

No que se refere ao futuro do modelo de negócio dentro desse mercado, o consenso é total por parte dos entrevistados que acreditam que ele irá se estabelecer como uma nova categoria dentro do setor gastronômico do país. Para P1, "os Food Trucks vão se instalar como um novo modelo dentro do setor gastronômico que caminha para sua profissionalização no mercado". Já o proprietário P2 afirma: "Esse modelo já está se consolidando, hoje você encontra Food Trucks no país inteiro". Por fim, P5 ressalta: "Food truck já é uma realidade no mundo inteiro, é uma nova categoria de negócio e tem que ser respeitado como tal".

Alguns Food Trucks que foram encontrados não puderam ser avaliados em termos de variação do faturamento por alguns motivos específicos que pudessem enviesar a pesquisa. Por exemplo, o Chilli na Rua é um Food Truck que não está em atividade com frequência regular, pois seu proprietário utiliza a capacidade ociosa de outro empreendimento (restaurante) para "tocar" o Food Truck. Os Food Trucks Açaí da Capital, Açaí Truck e Mix Açaí comercializam um produto muito sazonal, portanto não pode ser analisado devido ao pequeno período de análise. A Kombinni Coffee Truck não possui nenhum tipo de controle do faturamento, logo não é possível obter os dados para o cálculo da TVF. Os Food Trucks Shukran Rock \& Food e o Raf Food Truck fizeram pausa de atividade no período definido para análise por motivos de saúde de sócios e familiares. Logo não se obtiveram os dados necessários para a análise. A Komboleria fez uma pausa no mês de dezembro de 2014 para reforma do Truck, portanto o cálculo da TVF no período definido para pesquisa poderia enviesar a TVFM. O Corujinha Food Truck deixou de atuar dentro do modelo de negócio dos Food Truck para desenvolver um novo projeto chamado "Corujinha On the Road" e viajarão pelo mundo com o objetivo de conhecer pessoas, lugares, culturas, comidas, etc.

Revista Alcance - Eletrônica - vol. 23 - n. 3 - jul./set. 2016 
Gráfico 2: Relação - Tempo de Atividade x TVF

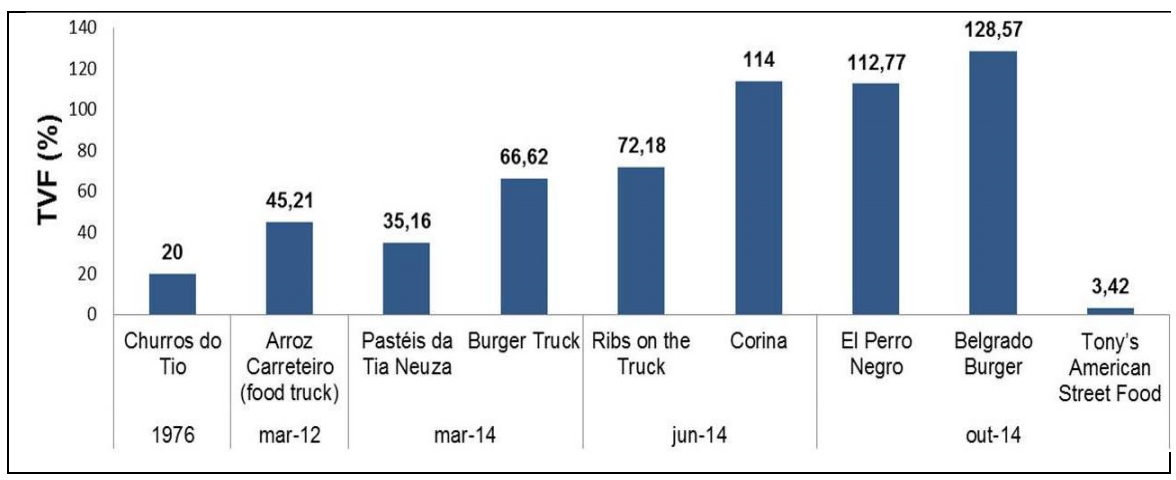

Fonte: Elaboração própria a partir de dados da pesquisa.

Como pode ser evidenciado no Gráfico 2, ao analisar a TVF dos Food Trucks relacionada ao seu tempo de atividade, é possível perceber que os empreendimentos mais jovens tendem a ter uma variação positiva maior que empreendimentos mais antigos. Esse fenômeno pode ser explicado pelos estudos de Mintzberg (1973), que afirma que empreendimentos jovens possuem uma curva de crescimento mais acentuada e à medida que atinge sua maturidade, esse crescimento passa a ser mais tímido.

\subsection{Análise de Desempenho}

Depois de selecionado os Food Trucks que já estavam em atividade desde a data início do intervalo de pesquisa e descartar da análise os empreendimentos que pudessem enviesar a TVFM por motivos já especificados, foi feito o cálculo da TVFM e chegou-se a um valor de $66,44 \%$.

\section{Gráfico 3: TVF dos Food Trucks em relação ao TVFM}

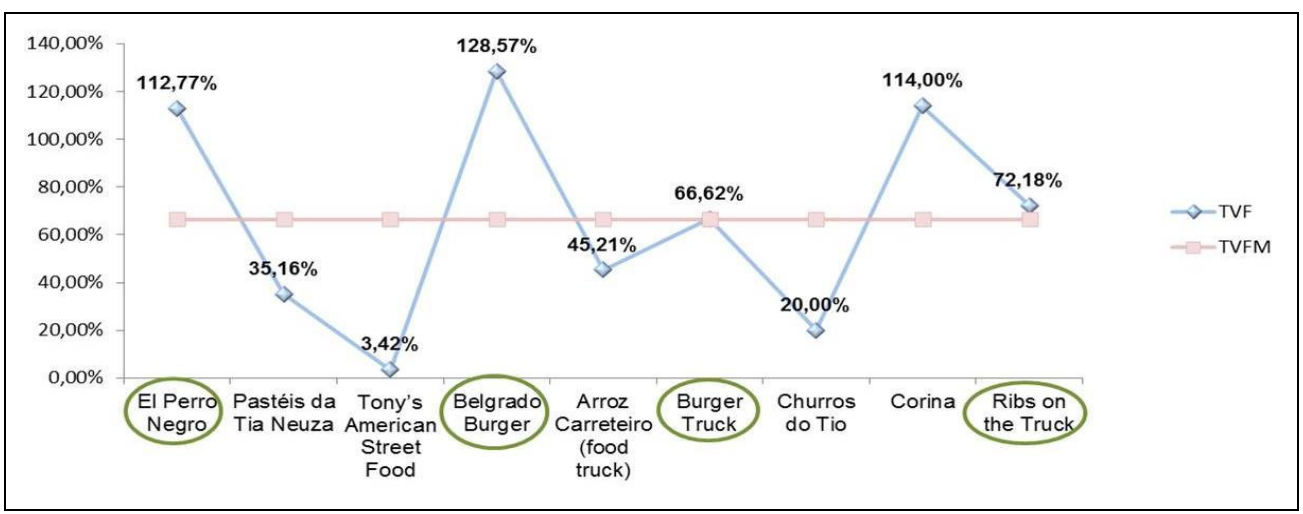

Fonte: elaboração própria a partir de dados da pesquisa.

O Gráfico 3 apresenta a taxa de variação do faturamento - TVF dos Food Trucks pesquisados em relação à taxa de variação do faturamento média - TVFM. É possível identificar que cinco deles possuem uma TVF acima da média, sendo que desses cinco, quatro estão dentro da categoria de refeição. Portanto os quatro que se inserem dentro da categoria refeição representa a amostra do presente estudo.

A distribuição das especialidades dos Food Trucks está dentro de três categorias: i) refeições, representando $69 \%$ do total; ii) bebidas, com a fatia de $12 \%$; e iii) sobremesas, que responde por $19 \%$ de Food Trucks no ano de 2015. Essa distribuição denota um grande bloco representado pelas refeições e outros dois menores representados por bebidas e sobremesas. Isso evidencia uma complementariedade entre as especialidades ofertadas dentro do mercado do DF, pois bebidas e sobremesas complementam o bloco maior que são as refeições. Esses dados corroboram as informações destacadas pela entrevistada P1, "Nosso modelo 
procura ainda trabalhar de maneira complementar, food trucks que se complementam em termos de produtos oferecidos".

\section{Gráfico 4: Porcentagem de Foof Trucks em 2015 por categoria}

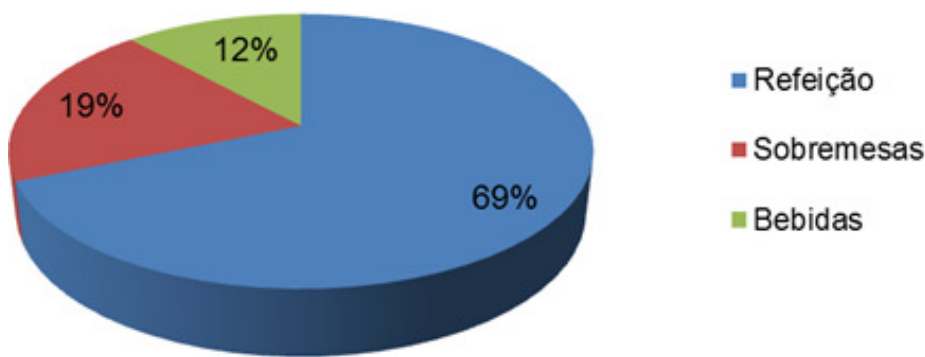

Fonte: Elaboração própria a partir de dados da pesquisa.

O Gráfico 4 demostra a distribuição das especialidades dos Food Trucks dentro de três categorias: refeições, bebidas e sobremesas. A distribuição exibida no Gráfico 4 denota um grande bloco representado pelas refeições e outros dois menores representados por bebidas e sobremesas. Isso evidencia uma complementariedade entre as especialidades ofertadas dentro do mercado do DF, pois bebidas e sobremesas complementam o bloco maior que são as refeições. Esses dados corroboram as informações destacadas pela entrevistada P1, "Nosso modelo procura ainda trabalhar de maneira complementar, food trucks que se complementam em termos de produtos oferecidos".

\subsection{Análise dos Recursos}

Nesta secção sintetizam-se os dados obtidos nas entrevistas de acordo com o modelo VRIO apresentado por Barney e Clark (2007). Ao sistematizar os dados, procurou-se identificar o potencial de retorno para as organizações dos recursos encontrados, logo foram apresentados os recursos geradores de vantagem competitiva sustentável, vantagem competitiva temporária, paridade competitiva e desvantagem competitiva para cada empreendimento estudado. Assim, utilizou-se para sistematizar as evidências encontradas, por meio da entrevista para cada um dos empreendimentos investigados, o Quadro 2, no que diz respeito aos recursos físicos, humanos, organizacionais e financeiros.

Quadro 2: Modelo com parte do quadro síntese das evidências encontradas para um Food Truck

\begin{tabular}{|c|c|c|c|c|c|c|c|}
\hline $\begin{array}{l}\text { Tipo de } \\
\text { recursos }\end{array}$ & $\begin{array}{l}\text { Recursos } \\
\text { encontrados } \\
\text { na entrevista }\end{array}$ & Empresa & V & $\mathbf{R}$ & I & 0 & Resultado \\
\hline Físicos & $\begin{array}{l}\text { Modelo do } \\
\text { Truck }\end{array}$ & $\begin{array}{l}\text { "Tenho um Truck maior que os outros, } \\
\text { então ele me permite ter uma estrutura } \\
\text { que produz mais que os outros" (...) } \\
\text { "Dentro podem trabalhar até } 5 \text { pessoas" } \\
\text { (...) "Apesar de existir algumas limitações } \\
\text { pelo tamanho do truck, Brasília é uma } \\
\text { cidade muito espaçosa, ela suporta muito } \\
\text { bem trucks maiores". }\end{array}$ & $X$ & $X$ & $X$ & $X$ & $\begin{array}{c}\text { Vantagem } \\
\text { Competitiva } \\
\text { Sustentável } \\
\text { (VCS) }\end{array}$ \\
\hline$\ldots$ & $\ldots$ & $\ldots$ & & & & & \\
\hline Humanos & Treinamento & $\begin{array}{l}\text { "Nosso treinamento foi zero" (...) } \\
\text { "Aprendemos a partiu da observação das } \\
\text { práticas dos lugares onde frequentamos". }\end{array}$ & $X$ & - & - & - & $\begin{array}{l}\text { Desvantagem } \\
\text { Competitiva } \\
\text { (DC) }\end{array}$ \\
\hline$\ldots$ & $\ldots$ & $\ldots$ & & & & & \\
\hline
\end{tabular}




\begin{tabular}{|c|c|c|c|c|c|c|c|}
\hline $\begin{array}{l}\text { Organiza- } \\
\text { cionais }\end{array}$ & $\begin{array}{l}\text { Qualidade } \\
\text { dos Produtos }\end{array}$ & $\begin{array}{l}\text { "Eu sempre tento usar os melhores } \\
\text { queijos, a melhor carne" (...) "Eu não } \\
\text { procuro produtos baratos, eu tento } \\
\text { entregar qualidade" (...) "Alguns trucks } \\
\text { entregam qualidade outros não". }\end{array}$ & $X$ & - & - & $X$ & $\begin{array}{l}\text { Paridade } \\
\text { Competitiva } \\
\text { (PC) }\end{array}$ \\
\hline$\ldots$ & $\ldots$ & $\ldots$ & & & & & \\
\hline Financeiros & Investimentos & $\begin{array}{c}\text { "Não estamos investindo nesse momento } \\
\text { no Ribs, pois estamos em um processo } \\
\text { de construção de outro truck (expansão), } \\
\text { então o investimento está sendo alocado } \\
\text { nele.". }\end{array}$ & $X$ & $X$ & - & $x$ & $\begin{array}{c}\text { Vantagem } \\
\text { Competitiva } \\
\text { Temporária } \\
\text { (VCT) }\end{array}$ \\
\hline$\ldots$ & $\ldots$ & $\ldots$ & & & & & \\
\hline
\end{tabular}

Analisando o Quadro 2, para cada um dos empreendimentos identificou-se que os recursos geradores de vantagem competitiva sustentável estão divididos entre capital físico, humano e organizacional. Ademais, se observou que a maior parte desses recursos é de capital humano.

\section{Quadro 4: Evidências de VCS x Desempenho}

\begin{tabular}{|c|c|c|}
\hline \multicolumn{3}{|c|}{ Empresa: Ribs On The Truck } \\
\hline \multicolumn{2}{|c|}{ Recursos fonte de VCS } & Desempenho \\
\hline Físicos & $\begin{array}{l}\text { - Design atrativo } \\
\text { - Estrutura Interna (do Truck) } \\
\text { - Matéria-prima exclusiva } \\
\text { - Equipamentos }\end{array}$ & $\begin{array}{l}\text {-Satisfazer o consumidor: } 6 \text { (Muito Bom) } \\
\text {-Reputação positiva: } 6 \text { (Muito Bom) } \\
\text {-Geração de lucro em tempos de baixa demanda: } 4 \\
\text { (Regular) }\end{array}$ \\
\hline Humanos & $\begin{array}{l}\text { - Experiência na área } \\
\text { - Network } \\
\text { - Conhecimento Técnico dos } \\
\text { Funcionários } \\
\text { - Bom atendimento }\end{array}$ & $\begin{array}{l}\text {-Número médio de clientes atendidos por mês (movimento } \\
\text { regular): } 2.500 \\
\text {-Ticket médio: } R \$ 20,00\end{array}$ \\
\hline $\begin{array}{c}\text { Organiza- } \\
\text { cionais }\end{array}$ & $\begin{array}{l}\text { - Receita própria } \\
\text { - Reputação da empresa } \\
\text { - Sistema de Controle e } \\
\text { Coordenação (Formal) } \\
\text { - Responsabilidade Social }\end{array}$ & -Fidelizar novos clientes: 6 (Muito Bom) \\
\hline
\end{tabular}




\begin{tabular}{|c|c|c|}
\hline \multicolumn{3}{|c|}{ Empresa: El Perro Negro } \\
\hline \multicolumn{2}{|c|}{ Recursos fonte de VCS } & \multirow{5}{*}{$\begin{array}{l}\text { Desempenho } \\
\text {-Satisfazer o consumidor: } 5 \text { (Bom) } \\
\text {-Reputação positiva: } 7 \text { (Excelente) } \\
\text {-Geração de lucro em tempos de baixa demanda: } 6 \text { (Muito } \\
\text { Bom) } \\
\text {-Número médio de clientes atendidos por mês (movimento } \\
\text { regular): } 2.500 \\
\text {-Ticket médio: } R \$ 12,69 \text { Fidelizar novos clientes: } 5 \text { (Bom) }\end{array}$} \\
\hline Físicos & $\begin{array}{l}\text { - Matéria-prima exclusiva } \\
\text { - Geração de energia }\end{array}$ & \\
\hline Humanos & - Bom atendimento & \\
\hline $\begin{array}{l}\text { Organiza- } \\
\text { cionais }\end{array}$ & - Variedade (Cardápio) & \\
\hline Financeiros & - Investimentos & \\
\hline \multicolumn{3}{|c|}{ Empresa: Burger Truck } \\
\hline \multicolumn{2}{|c|}{ Recursos fonte de VCS } & \multirow{5}{*}{$\begin{array}{l}\text { Desempenho } \\
\text {-Satisfazer o consumidor: } 6 \text { (Muito Bom) } \\
\text {-Reputação positiva: } 5 \text { (Bom) } \\
\text {-Geração de lucro em tempos de baixa demanda: } 4 \\
\text { (Regular) } \\
\text {-Número médio de clientes atendidos por mês (movimento } \\
\text { regular): } 1.500 \\
\text {-Ticket médio: } R \$ 18,00 \text { Fidelizar novos clientes: } 5 \text { (Bom) }\end{array}$} \\
\hline Físicos & $\begin{array}{l}\text { - Modelo do Truck } \\
\text { - Geração de Energia }\end{array}$ & \\
\hline Humanos & $\begin{array}{l}\text { - Network } \\
\text { - Conhecimento Técnico dos } \\
\text { Funcionários } \\
\text { - Bom Atendimento } \\
\text { - Conhecimento de Gestão }\end{array}$ & \\
\hline $\begin{array}{l}\text { Organiza- } \\
\text { cionais }\end{array}$ & $\begin{array}{l}\text { - Qualidade dos Produtos } \\
\text { - Reputação da Empresa } \\
\text { - Comunicação Externa }\end{array}$ & \\
\hline Financeiros & 10. Investimentos & \\
\hline \multicolumn{3}{|c|}{ Empresa: Belgrado Burger } \\
\hline \multicolumn{2}{|c|}{ Recursos fonte de VCS } & \multirow{4}{*}{$\begin{array}{l}\text {-Satisfazer o consumidor: } 6 \text { (Muito Bom) } \\
\text {-Reputação positiva: } 6 \text { (Muito Bom) } \\
\text {-Geração de lucro em tempos de baixa demanda: } 4 \\
\text { (Regular) } \\
\text {-Número médio de clientes atendidos por mês (movimento } \\
\text { regular): Ticket médio: } R \$ 20,00 \\
\text {-Fidelizar novos clientes: } 6 \text { (Muito Bom) }\end{array}$} \\
\hline Físicos & $\begin{array}{l}\text { - Modelo do Truck } \\
\text { - Equipamentos }\end{array}$ & \\
\hline Humanos & $\begin{array}{l}\text { - Treinamento } \\
\text { - Bom Atendimento } \\
\text { - Agilidade } \\
\text { - Gestão Familiar }\end{array}$ & \\
\hline $\begin{array}{l}\text { Organiza- } \\
\text { cionais }\end{array}$ & $\begin{array}{l}\text { - Receita Própria } \\
\text { - Capacidade de Inovação }\end{array}$ & \\
\hline
\end{tabular}

Fonte: Dados da própria pesquisa.

O Quadro 4 traz, além dos recursos fontes de VCS, o desempenho identificado em cada empreendimento de acordo com a percepção do proprietário, por meio de questões em uma escala likert de 1 a 7 , como pode ser visualizado no Anexo 1.

Visualizando o Gráfico 5, é possível observar que existe semelhança no desempenho entre as quatro empresas estudadas pois, no geral, todas apresentam bom desempenho para todos os indicadores. O El Perro Negro, apesar de ter um desempenho superior em gerar lucro em tempos de crise, mostra desempenho inferior em satisfazer o consumidor. Logo, não se pode dizer que os resultados são distintos entre essas organizações. Ainda que possuam um desempenho semelhante, sabe-se que a combinação dos recursos de cada organização contribui de forma significativa para o seu desempenho (Barney, 1991), identificado nas quatro empresas estudadas. 0 Gráfico 5 apresenta as variáveis de desempenho abordadas na entrevista e as respectivas empresas estudadas. 


\section{Gráfico 5: Relação Variáveis de Desempenho x Empresas}

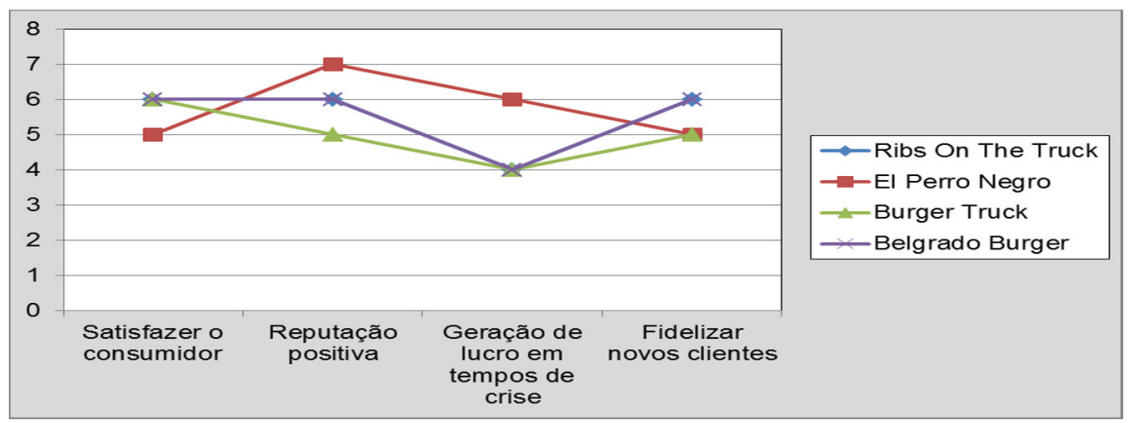

Fonte: Elaboração própria a partir de dados da pesquisa.

Portanto, a forma como cada organização chega a esse desempenho é distinta, pois o arranjo de recursos fontes de VCS para cada empreendimento, ainda que com elementos comuns, não é o mesmo. Essa diferença vai de encontro com o conjunto idiossincrático de recursos apontados pela teoria da VBR (Barney, 1991).

Além disso, na classificação dos Recursos Competitivos nas Empresas, em termos de Vantagem Competitiva Sustentável (VCS), Vantagem Competitiva Temporária (VCT), Paridade Competitiva (PC) e Desvantagem Competitiva (DC), evidenciou-se um total de vinte e cinco recursos nas quatro empresas estudadas. Desse total, constatou-se que dez apareceram em pelo menos duas organizações, sendo sua maioria de capital físico. Esses recursos foram: modelo do truck, matéria-prima exclusiva, geração de energia, equipamentos, network, conhecimento técnico dos funcionários, bom atendimento, receita própria, reputação da empresa e investimentos.

Observaram-se também duas empresas, O Ribs On The Truck e Burger Truck, que tiveram um maior número de recursos geradores de VCS em comum. Foram identificados nestes dois empreendimentos, network, conhecimento técnico dos funcionários, bom atendimento e reputação da empresa como recursos fonte de VCS. Observa-se que dentre as quatro empresas estudadas, estas possuem um tempo maior em atividade, portanto atenta-se para uma possível relação que pode ser explicada pela ambiguidade causal de recursos como network e reputação da empresa que dependem do tempo para sua construção (Barney, 1991).

O recurso que se destaca como gerador de vantagem competitiva sustentável é o bom atendimento (vide Quadro 5), pois ele é comum às quatro empresas estudadas. Isso parece mostrar que esse recurso pode ser definidor de VCS para esse modelo de negócio. Note-se que entre os recursos, há aqueles mais idiossincráticos, como a "receita própria" ou "gestão familiar", mas o atendimento que está presente entre todos cumpre o papel de gerar vantagem competitiva, dentro das lacunas sistema de negócio e organização e qualidade da gestão apontadas por Coyne (1986). Essas lacunas estão suportadas fortemente no que se pode chamar de decisões estratégicas do empresário (a). Além disso, o bom atendimento tem o que Barney (1991) nomeou como ambiguidade causal, ou seja, pode perceber o efeito, mas é difícil determinar a causa que gerou o recurso.

Quadro 5: Destaques entre os Recursos Identificados

\begin{tabular}{|c|c|c|c|}
\hline Tipo de recurso & Recursos de destaque & Tipo de recurso & Recursos de destaque \\
\hline Capital Físico & $\begin{array}{l}\text { Modelo do Truck } \\
\text { Matéria-Prima Exclusiva } \\
\text { Geração de Energia } \\
\text { Equipamentos }\end{array}$ & Capital Humano & $\begin{array}{l}\text { Network } \\
\text { Conhecimento Técnico dos } \\
\text { Funcionários } \\
\text { Bom Atendimento }\end{array}$ \\
\hline Capital Organizacional & $\begin{array}{l}\text { Receita Própria } \\
\text { Reputação da Empresa }\end{array}$ & Capital Financeiro & Investimentos \\
\hline
\end{tabular}

Fonte: Elaborado pelo próprio autor a partir de dados da pesquisa. 
Feita uma comparação no Quadro 6 entre os resultados encontrados no presente trabalho com de alguns outros estudos abordados no referencial teórico, pôde-se identificar alguns recursos em comum, com destaque para a reputação da empresa.

Quadro 6: Recursos comuns aos estudos apresentados no referencial teórico

\begin{tabular}{|l|l|}
\hline Recursos - literatura & Estudos \\
\hline Reputação & $\begin{array}{l}\text { Hayashi, Baraniuk e Bulgacov (2006); Hexsel e Lagreca (2007); Pavão, Sehnem } \\
\text { e Hoffmann (2011) }\end{array}$ \\
\hline Equipamentos & Barcelos, Marcon e Mello (2011) e Gohr et al. (2011) \\
\hline Investimentos & Barcelos, Marcon e Mello (2011) \\
\hline Network & Pavão, Sehnem e Hoffmann (2011) \\
\hline
\end{tabular}

Fonte: Dados da própria pesquisa.

*O recurso identificado neste estudo é a imagem da marca, porém pode ser entendida como reputação.

Note-se que no estudo sobre pequenas empresas do setor alimentício feito por Hayashi, Baraniuk e Bulgacov (2006), entre os recursos apontados estava a reputação. Contudo, aquele trabalho versou sobre a indústria de transformação; enquanto este trata de serviços, por isso se acredita que ter aparecido o recursos bom atendimento é natural. Ainda sobre a reputação, note-se que ela cumpre os requisitos de Barney (1991) para ser um recurso competitivo. E com relação a ser imperfeitamente imitável (Barney, 1991), ele cumpre mais de uma condição, conquanto poder haver tanto a dependência de trajetória como a ambiguidade causal.

o Gráfico 6 permite visualizar, uma vez mais, a maior proximidade entre o Ribs On The Truck e o Burger Truck no que diz respeito aos arranjos de recursos encontrados dentro das empresas. Ainda é possível observar que essas duas organizações que estão atuando há mais tempo no mercado possuem números mais elevados de recursos geradores de VCS e ainda um número menor de desvantagens competitivas em relação às outras duas organizações. Como escreve Coyne (1986), se um produtor vende seus serviços, gerando lucro, ele dispõe de uma vantagem competitiva com os consumidores que optaram por comprar dele e não de seus competidores, $e$ no caso dessas duas empresas, ao parecer isso essa vantagem é sustentável, em função de sua presença no mercado há mais tempo que as demais.

Gráfico 6: Fonte dos Recursos nas Empresas

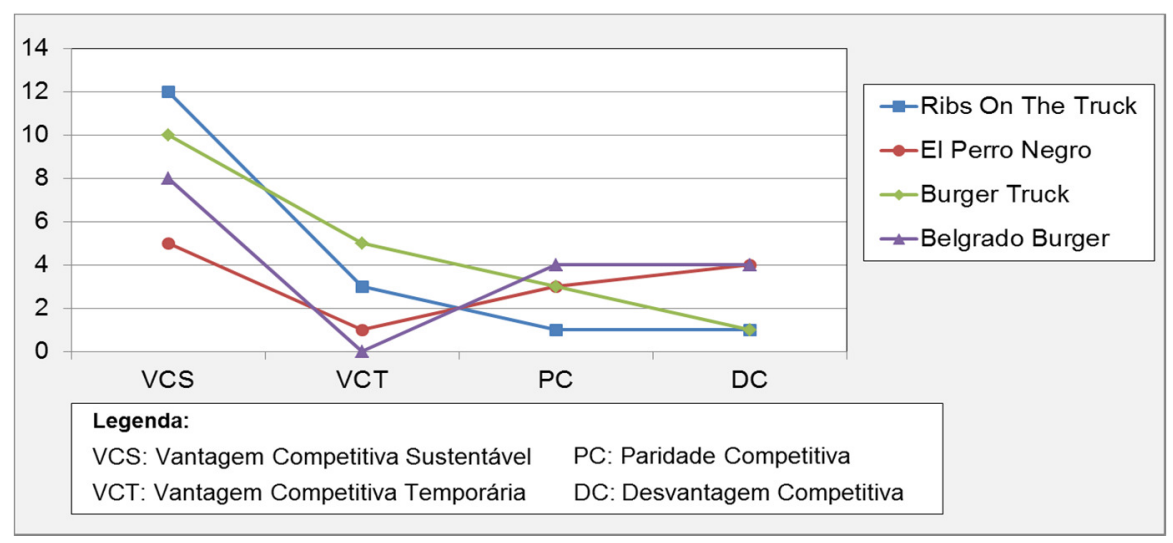

Fonte: Elaborado pelo próprio autor a partir do original de Pavão, Sehnem e Hoffmann (2011, p.237).

Alguns recursos surgiram de maneira isolada, como gestão familiar, conhecimentos de gestão e variedade (cardápio). Isso se dá pela heterogeneidade desses empreendimentos. Como já discutido por Mintzberg (1973), é comum encontrar grandes diferenças entre pequenas empresas, ainda que sejam do mesmo ramo de

Revista Alcance - Eletrônica - vol. 23 - n. 3 - jul./set. 2016 
atuação, pois é algo característico deste porte de organização. Outros estudos abordados no referencial teórico deste presente trabalho vêm ao encontro das evidências encontradas, como Eriksen e Knudsen (2003), que pesquisaram pequenas e médias empresas na Dinamarca e apontaram o efeito firma como maior impactante no desempenho dessas organizações. Isso evidencia que existem inúmeras peculiaridades dentro de cada organização que impactam no seu desempenho.

Como escreveram Hexsel e Lagreca (2007), uma das circunstâncias que dificulta o desenvolvimento das PME é que essas tendem a atuar em setores fragmentados, em que são baixas as barreiras à entrada, o processo competitivo é intenso, confirmando a questão das baixas barreiras de entrada e alta competição. Contudo, essas empresas parecem ter conseguido responder o paradoxo de Daft (1999), ao basear suas estratégias em uma gama maior de recursos, já que em um cenário competitivo, elas precisam depender mais de seus recursos que de seu ambiente, concluem Hexsel e Lagreca (2007).

\section{CONCLUSÕES}

Este estudo teve por objetivo identificar os recursos dentro dos Food Trucks que gerassem vantagem competitiva sustentável e que por sua vez possibilitassem que esses empreendimentos obtivessem um desempenho acima da média dentro do setor. Para concretizá-lo, realizou-se uma pesquisa por meio de estudos de caso e de coleta de dados por meio de entrevistas semiestruturadas, portanto as fontes de dados foram de caráter primário.

O referencial teórico apresentou conceitos e estudos de autores que escreveram sobre as temáticas de estratégia organizacional, vantagem competitiva e desempenho. Para pesquisa utilizou-se a concepção de Barney (1991) no que diz respeito aos recursos e o modelo aplicado foi desenvolvido por Barney e Clark (2007).

Dentro das organizações estudadas, foi identificado um total de 25 recursos, sendo que 10 deles se destacaram por estarem presentes em duas ou mais organizações. Os principais recursos foram: modelo do truck, matéria-prima exclusiva, geração de energia, equipamentos, network, conhecimento técnico dos funcionários, bom atendimento, receita própria, reputação da empresa e investimentos.

O grande destaque se deu para o bom atendimento, recurso que não havia sido apontado em outros estudos (nacionais e internacionais) como fonte de vantagem competitiva. Esse recurso foi identificado em todas as organizações estudadas como fonte de vantagem competitiva sustentável. Isso pode indicar que este também é um recurso definidor de vantagem competitiva sustentável para esse modelo de negócio, o que o torna um recurso altamente estratégico para o objeto de estudo, isto é, em food trucks o atendimento está intrínseco ao modelo de negócio, sendo um recurso interno distintivo que oferece desempenho superior (BARNEY, 1991; MOHR et al, 2011).

Percebeu-se também que o tempo de atuação das organizações pode ter um impacto no arranjo dos recursos que são encontrados e explorados por elas. Isso pelo fato de as duas organizações mais antigas possuírem maior semelhança em suas combinações de recursos do que as organizações mais jovens. Porém não se pode generalizar essa relação e é preciso mais estudos que comprovem que essa relação existe de fato.

Ainda assim é importante ressaltar que foi observada uma série de recursos isolados, encontrados em apenas uma das organizações. Isso confirma algumas evidências apontadas por Mintzberg (1973) de que organizações de pequeno porte possuem um grande número de diferenças entre si ainda que dentro do mesmo ramo de atuação e reforça a questão da heterogeneidade descrita por Barney (1991), como característica de todas as empresas, desde o ponto de vista de seus recursos. Algo que está diretamente relacionado ao fato do processo de formulação estratégica, dentro dessas organizações, estar fortemente dependente das características e cultura do proprietário e gestor do empreendimento.

Como limitação da pesquisa, assume-se que a amostra foi intencional, relacionada a pequenas empresas que foram destaque em crescimento e que, portanto, não se podem fazer generalizações. Contudo, pôde-se supor que os resultados deram validade empírica para evidências teóricas apresentadas ao longo da discussão para a realidade das pequenas empresas componentes do estudo. Outra limitação é o intervalo de tempo definido para a pesquisa, que tem sua justificativa no caráter inovador do modelo que ainda é recente no país, considerados os estudos já publicados. Esse período de tempo curto pode trazer ainda uma visão limitada sobre o desempenho, já que este dá respostas melhores quando analisado ao longo do tempo. Uma última limitação é o viés de fonte 
comum, já que tanto os recursos (variável independente) como o desempenho (variável dependente) foram informados pelos proprietários.

Como sugestões para pesquisas futuras recomenda-se que o intervalo de pesquisa seja ampliado para um ano ou mais, podendo visualizar o efeito de eventos sazonais sobre o setor, como o clima. 0 aumento da amostra ou utilização de uma amostra mais diversificada no que diz respeito à especialidade. Além disso, podemse utilizar também outros indicadores de desempenho.

\section{REFERÊNCIAS}

ARAGÓN-CORREA, J. Alberto; HUTARDO-TORRES, Nuria; SHARMA, Sanjay; GARCÍA-MORALES, Víctor J. Environmental strategy and performance in small firms: a resource-based perspective. Journal Environmental Management, v 88, p. 88-103, 2008.

BARCELOS, L.; MARCON, R.; MELLO, R. B. Evidenciação de Recursos e Capacidades Organizacionais: Um estudo à Luz da RBV. Revista de Negócios, Blumenau, v16, n.3, p.113 - 134, Julho/Setembro, 2011.

BARNEY, J. B. Firm resources and sustained competitive advantage. Journal of Management, v. 17, n 1, p. 99120, 1991.

BARNEY, J. B.; CLARK, D. N. Resource-Based Theory: creating and sustaining competitive advantage. New York: Oxford University, 2007.

BARNEY, J.B; HESTERLY, W.S. Administração Estratégica e Vantagem Competitiva: casos brasileiros. São Paulo: Pearson, 2007.

BRUYNE, P. Dinâmica da Pesquisa em Ciências Sociais: os pólos da prática metodológica. Rio de Janeiro: Francisco Alves, 1991.

COYNE, K. P. Sustainable Competitive Advantage - what it is, what it isn't. Business Horizons: 1986.

DAFT, R. Administração. Rio de Janeiro: LTC - Livros Técnicos e Científicos Editora S.A, 1999.

ERIKSEN, B.; KNUDSEN, T. Industry and firm interaction: Implication for profitability. Journal of Business Research, v. 56, p. 191-199, 2003.

GOHR, C. F.; SANTOS, L. C.; BURIN, C. B.; MARQUES, M. S.; ARAI, R. M. Recursos estratégicos e vantagem competitiva: Aplicação do modelo VRIO em uma organização do setor sucroalcooleiro. Revista Gestão Organizacional, v. 4, n. 1, jan./jul., 2011.

DIERICKX, I.; COOL, K. Asset stock accumulation and sustainability of competitive advantage. Management Science. v. 33, n. 12, dez. 1989.

GONÇALVES, Carlos Alberto; COELHO, Mariana de F.; SOUZA, Érika Márcia. VRIO: Vantagem competitiva sustentável pela organização. Rev. Ciênc. Admin., Fortaleza, v. 17, n. 3, p. 819-855, set./dez, 2011.

HAYASHI, P.; BARANIUK, J. A.; BULGACOV, S. Mudanças de Conteúdo Estratégico em Pequenas Empresas de Massas Alimentícias. Revista de Administração Contemporânea, v. 10, n. 3, Jul./Set. 2006.

HERZOG, Ludger Teodoro. Aproximación a la ventaja competitiva com base em los recursos. Boletin de Estudos Económicos, v. LVI, n. 172, 2001

HEXSEL, A. E.; LAGRECA, R. A construção e sustentação da vantagem competitiva por pequenas e médias empresas: o caso da Baldo. Revista Eletrônica de Administração, v. 13, n. 3. 2007.

HOFFMAN, Nicole P. An examination of the "Sustainable competitive advantage" concept: past, present, and future. Academy of Marketing Science Review, n. 4, p. 1-16, 2000.

KRETZER, Jucélio; MENEZES, Emílio Araújo. A importância da visão baseada em recursos na explicação da vantagem competitiva. Revista de Economia Mackenzie, v. 4, n. 4, p. 63-87, 2008.

MOHR, Jakki; SENGUPTA, Sanjit; SLATER, Stanley; LUCHT, Richard. Marketing para mercados de alta tecnologia e de inovações. São Paulo: Pearson Prentice Hall, 2011.

MINTZBERG, H. Strategy-making in three modes. California Management Review, v. 16, n. 2, p. 44-53, 1973.

Revista Alcance - Eletrônica - vol. 23 - n. 3 - jul./set. 2016 
PAVÃO, Y. M. P.; SEHNEM, S.; HOFFMANN, V. E. Análise dos recursos organizacionais que sustentam a vantagem competitiva. R.Adm., São Paulo, v.46, n.3, p.228-242, jul./ago./set. 2011.

PORTER, M.E. Competitive advantage: Creating and sustaining superior performance. Nueva York: The Free Press, 1985.

PORTER, M. E. Estratégia Competitiva. Rio de Janeiro: Campus 1991.

RIBEIRO, Ronaldo; ROSSETO, Carlos Ricardo; VERDINELLI, Miguel Angel. Comportamento estratégico da empresa e a visão baseada em recursos: um estudo no setor varejista de material de construção. Gestão \& Produção. São Carlos, v 18, n. 1, p. 175-192, 2011.

SEBRAE- Serviço Brasileiro de Apoio às Micro e Pequenas Empresas. Participação das Micro e Pequenas Empresas na Economia Brasileira. Brasília-DF: Sebrae, 2014.

TRIVIÑOS, Augusto N. S. Introdução à pesquisa em ciências sociais: a pesquisa qualitativa em educação. São Paulo: Atlas, 1994.

YIN, Robert K. Estudo de caso - planejamento e métodos. 4. ed. Porto Alegre: Bookman, 2010. 


\section{ANEXO 1}

Roteiro de entrevista

\begin{tabular}{|c|c|c|c|c|c|c|c|c|c|c|}
\hline & & Objetivo & \multicolumn{7}{|c|}{ Questões } & Observações \\
\hline 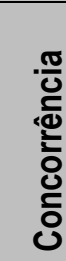 & & $\begin{array}{l}\text { Caracterizar } 0 \\
\text { mercado de oferta* }\end{array}$ & \multicolumn{7}{|c|}{$\begin{array}{l}\text { 1. Na sua percepção, como está o mercado para Food Trucks em } \\
\text { BSB? } \\
\text { 2. Quem são seus concorrentes? } \\
\text { 3. Na sua opinião, o Food Truck é uma moda ou uma tendência? }\end{array}$} & $\begin{array}{l}\text { Estimular no sentido de } \\
\text { descobrir se os } \\
\text { restaurantes também são } \\
\text { concorrentes. }\end{array}$ \\
\hline \multirow{10}{*}{\multicolumn{2}{|c|}{ 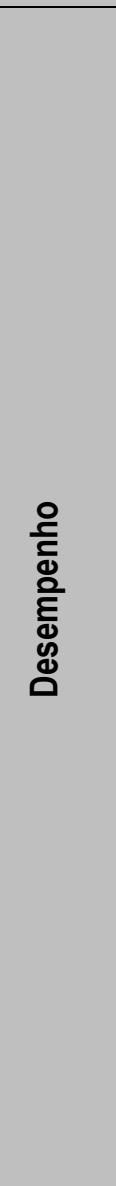 }} & \multirow{10}{*}{$\begin{array}{l}{ }^{* *} \text { Identificar a } \\
\text { percepção do } \\
\text { proprietário em } \\
\text { relação ao seu } \\
\text { desempenho. }\end{array}$} & \multicolumn{7}{|c|}{$\begin{array}{l}\text { 4. Indique o desempenho atual do seu negócio, nos seguintes } \\
\text { critérios: } \\
\text { a) Bem-sucedido em satisfazer o consumidor. }\end{array}$} & \multirow[t]{9}{*}{$\begin{array}{l}\text { Facilitar o vínculo entre os } \\
\text { recursos encontrados e o } \\
\text { desempenho do } \\
\text { empreendimento. }\end{array}$} \\
\hline & & & \multirow{2}{*}{\multicolumn{7}{|c|}{ 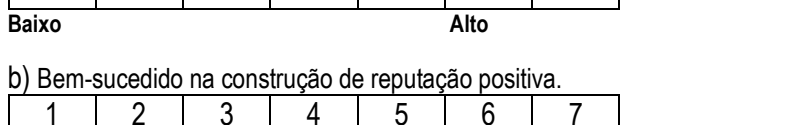 }} & \\
\hline & & & & & & & & & 7 & \\
\hline & & & \multicolumn{7}{|c|}{$\begin{array}{l}\text { Baixo Alto } \\
\text { C) Bem-sucedido na geração de lucro em tempos de crise por baixa demanda } \\
\text { (lima, proibições). }\end{array}$} & \\
\hline & & & 1 & 2 & 3 & 4 & 5 & 6 & 7 & \\
\hline & & & \multicolumn{7}{|c|}{$\begin{array}{l}\text { Baixo } \\
\text { d) Resposta eficaz para as mudanças do mercado. }\end{array}$} & \\
\hline & & & \multicolumn{7}{|c|}{$\begin{array}{l}\text { Baixo } \\
\text { 5. Indique o número total de empregados no início do } \\
\text { empreendimento e atualmente. } \\
\text { 6. Qual o número médio de clientes atendidos no mês? } \\
\text { 7. Qual o ticket médio do seu negócio? } \\
\text { 8. Como você avalia o desempenho do seu negócio, em uma escala } \\
\text { de } 1 \text { a 7, em fidelizar novos clientes? }\end{array}$} & \\
\hline & & & 1 & 2 & 3 & 4 & 5 & 6 & 7 & \\
\hline & & & \multicolumn{7}{|c|}{$\begin{array}{l}\text { Alto } \\
\text { 9. Indique o desempenho de sua empresa, em uma escala de } 1 \text { a } 7 \text {, } \\
\text { considerando que } 4 \text { é um desempenho médio do setor de Food Truck }\end{array}$} & \\
\hline & & & \multicolumn{7}{|c|}{ Baixo $\quad$ Médio (Setor) } & \\
\hline & $\frac{.0}{\frac{0}{0}}$ & $\begin{array}{l}\text { Identificar os recursos } \\
\text { existentes nos } \\
\text { empreendimentos } \\
\text { selecionados } \\
\end{array}$ & \multicolumn{7}{|c|}{$\begin{array}{l}\text { 10.Quais recursos físicos você acredita possuir e usar? Como eles } \\
\text { são aplicados no seu negócio? (=O) } \\
\text { 11. Quais desses recursos impactam em seu faturamento } \\
\text { diretamente, ou geram valor? Explique. (=V) } \\
\text { 12. Na sua percepção quantos de seus concorrentes também } \\
\text { possuem esses recursos? (=R) } \\
\text { 13. Na sua percepção, esses recursos são difíceis de serem } \\
\text { imitados ou substituídos por seus concorrentes? Explique. (=I) }\end{array}$} & $\begin{array}{l}\text { Ex: Equipamentos; } \\
\text { estrutura física (próprio } \\
\text { truck); tecnologia } \\
\text { (produção e gestão); em } \\
\text { relação à concorrência; } \\
\text { variedade de produtos } \\
\text { (cardápio); acesso a } \\
\text { matéria-prima; localização } \\
\text { geográfica (Mobilidade); } \\
\text { Armazenamento } \\
\text { (estoque); Ambiente } \\
\text { (arquitetura, layout). }\end{array}$ \\
\hline
\end{tabular}

Continua. 


\begin{tabular}{|c|c|c|c|}
\hline & Objetivo & Questões & Observações \\
\hline 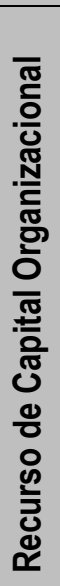 & $\begin{array}{l}\text { Identificar os recursos } \\
\text { existentes nos } \\
\text { empreendimentos } \\
\text { selecionados }\end{array}$ & $\begin{array}{l}\text { 14. Quais recursos organizacionais você acredita possuir e usar? } \\
\text { Como eles são aplicados no seu negócio? }(=0) \\
\text { 15. Quais desses recursos impactam em seu faturamento } \\
\text { diretamente, ou geram valor? Explique. }(=\mathrm{V}) \\
\text { 16. Na sua percepção quantos de seus concorrentes também } \\
\text { possuem esses recursos? (=R) } \\
\text { 17. Na sua percepção, esses recursos são difíceis de serem } \\
\text { imitados ou substituídos por seus concorrentes? Explique. }(=I)\end{array}$ & $\begin{array}{l}\text { Ex: O produto (receita } \\
\text { própria); Reputação da } \\
\text { empresa; imagem da } \\
\text { Empresa; história; } \\
\text { capacidade de inovação da } \\
\text { empresa; comunicação } \\
\text { interna; marketing e } \\
\text { propaganda sistemas de } \\
\text { controle e coordenação; } \\
\text { sistemas formais e } \\
\text { informais; cultura } \\
\text { organizacional; clima } \\
\text { organizacional; } \\
\text { responsabilidade social; } \\
\text { qualidade dos produtos; }\end{array}$ \\
\hline 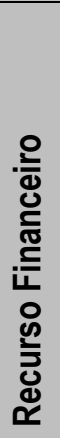 & $\begin{array}{l}\text { Identificar os recursos } \\
\text { existentes nos } \\
\text { empreendimentos } \\
\text { selecionados }\end{array}$ & $\begin{array}{l}\text { 18. Quais recursos financeiros você acredita possuir e usar? } \\
\text { Como eles são aplicados no seu negócio? (=O) } \\
\text { 19. Quais desses recursos impactam em seu faturamento } \\
\text { diretamente, ou geram valor? Explique. (=V) } \\
\text { 20. Na sua percepção quantos de seus concorrentes também } \\
\text { possuem esses recursos? (=R) } \\
\text { 21. Na sua percepção, esses recursos são difíceis de serem } \\
\text { imitados ou substituídos por seus concorrentes? Explique. (=I) }\end{array}$ & $\begin{array}{l}\text { Ex: preço baixo, (estrutura } \\
\text { de custos enxuta), } \\
\text { investimentos em práticas } \\
\text { de gestão de pessoas, } \\
\text { investimentos em } \\
\text { infraestrutura, capital de } \\
\text { giro, formas de pagamento, } \\
\text { investimentos em } \\
\text { comunicação (publicidade e } \\
\text { propaganda). }\end{array}$ \\
\hline
\end{tabular}

Fonte: Elaboração própria e também baseada em Hoffmann (2003), como indicado

* Para esse objetivo as informações foram obtidas na internet, como já indicado.

** As questões de número 4 a 9 foram adaptadas de Hoffmann, 2003. 